\title{
Statistical Solutions for a Nonautonomous Modified Swift-Hohenberg Equation
}

\author{
Jintao Wang ${ }^{1}$, Xiaoqian Zhang ${ }^{1}$, and Caidi Zhao ${ }^{1}$ \\ ${ }^{1}$ Wenzhou University
}

May 1, 2021

\begin{abstract}
We consider the nonautonomous modified Swift-Hohenberg equation $\$ \$ u_{-} \mathrm{t}+\backslash$ Delta $2 \mathrm{u}+2 \backslash$ Delta $\mathrm{u}+\mathrm{au}+\mathrm{b}|\backslash \mathrm{nabla} \mathrm{u}|^{\wedge} 2+\mathrm{u}^{\wedge} 3=\mathrm{g}(\mathrm{t}, \mathrm{x}) \$ \$$ on a bounded smooth domain $\$ \backslash$ Omega $\backslash$ subset $\backslash R^{\wedge} n \$$ with $\$ n \backslash$ leqslant $3 \$$. We show that, if $\$|b|<4 \$$ and the external force $\$ \mathrm{~g} \$$ satisfies some appropriate assumption, then the associated process has a unique pullback attractor in the Sobolev space \$H_0^2(\Omega)\$. Based on this existence, we further prove the existence of a family of invariant Borel probability measures and a statistical solution for this equation.
\end{abstract}

\section{Hosted file}

Manuscript_Wang-Zhang-Zhao.pdf available at https://authorea.com/users/411314/articles/ 520393-statistical-solutions-for-a-nonautonomous-modified-swift-hohenberg-equation

\section{Hosted file}

Manuscript_Wang-Zhang-Zhao.tex available at https://authorea.com/users/411314/articles/ 520393-statistical-solutions-for-a-nonautonomous-modified-swift-hohenberg-equation 